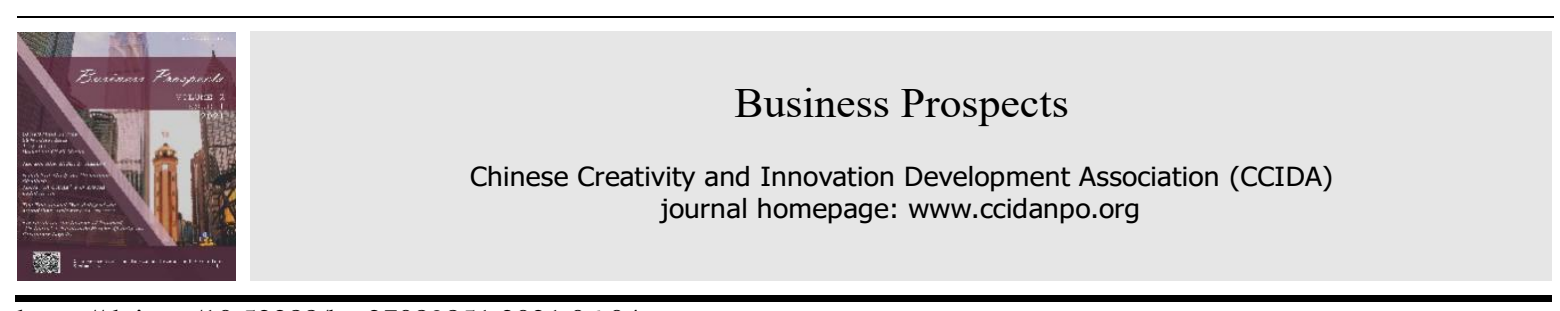

https://doi.org/10.52288/bp.27089851.2021.06.04

\title{
Research on Sustainable Development Strategy of Live E-Commerce
}

\author{
Gong-Jian Zhou ${ }^{1, *}$ \\ ${ }^{1}$ Xiamen University Tan Kah Kee College \\ * Correspondence:63223748@qq.com
}

Received: 2021.02.02; Accepted: 2021.04.06; Published: 2021.06.01

\begin{abstract}
Live e-commerce is the hottest and most eye-catching focus topic at present, and it is also a new form and trend of e-commerce marketing. It has become the main business and profit channel for the integrated development of major live broadcast platforms and e-commerce platforms. In 2020, the proposal of the new national infrastructure concept and the announcement of the new occupation of "Internet Marketer" have strengthened the new economic power of live broadcasting and provided new impetus for small, medium, and micro e-commerce enterprises to increase income and create efficiency. Starting from the background of live e-commerce, this paper analyzes the forms of domestic live e-commerce, expounds the impact of live ecommerce on e-commerce and the challenges it faces, and puts forward corresponding development strategies to strengthen the ecological construction of live e-commerce, promote the sustainable development of live new economy and the transformation and upgrading of e-commerce.
\end{abstract}

Keywords: Live E-Commerce; E-Commerce Platform; Shopping Experience; Live Form; Development Strategy

\section{Foreword}

In recent years, with the rapid development of Internet technology, high-end manufacturing and other high-tech industries, personal service terminal devices such as smart phones and tablet computers and communication devices such as $4 \mathrm{G}$ wireless network and WiFi sharing network have entered thousands of households. In addition, the huge demand market for network users and Internet products has created favorable conditions for the integration of e-commerce and live video (Zhong, 2020).

Since the online live shopping function of e-commerce platform in 2016, live e-commerce has developed rapidly, and has become a new mode for traditional e-commerce to maintain the flow dividend and redistribute the flow pattern. The economic effect of Internet celebrity has become increasingly prominent (Jiang, 2020). After more than four years of development, more and more e-commerce platforms, video live broadcasting platforms, MCN organizations / anchors, and brand manufacturers have participated in the live broadcasting ecommerce industry. The industrial ecology has basically taken shape, and the live broadcasting e-commerce industry has entered a period of rapid development (Jia and Zhang, 2020).

\section{Background of Live E-Commerce}

Live e-commerce is an emerging Internet product that combines e-commerce marketing and video live broadcasting, and it is also an inevitable product of the development of modern Internet. With the rapid development of high and new technology, especially the popularity of all kinds of smart phones, tablet computers and 4G networks, people can chat and shop online quickly, conveniently and in real time anytime and anywhere, and cultivate the habit of mobile Internet and e-commerce shopping. The development and application of various social software, video platform software and payment software enrich consumers' online entertainment and shopping behavior (Xie, 2020). The wide application of smart phones with high pixel and strong hardware performance and Internet technologies such as video barrage and online live broadcasting has 
enhanced the universality and interaction between video live broadcasting and consumers, and provided technical support for live broadcasting e-commerce. At this stage, the video live broadcast is blooming and thriving in the whole industry.

In 2016, the success of the live broadcast of the video broadcast was brought to the social focus. Every industry actively tried video live broadcast, such as panda live broadcast, short video of shaking, YY entertainment show, PPTV sports live broadcast, etc. All of which were successful and led the rise of the national broadcast which made the business smell the opportunity. Traditional e-commerce needs to break the bottleneck and seek development (Gao, 2020). The traditional e-commerce marketing methods are commodity discount, low price clearance, cash in advance, pre-sale, crowdfunding, and shopping gifts. Traditional e-commerce graphic explanation is slightly monotonous, uninteresting, and not attractive. In addition, the frequent price fluctuations of e-commerce products make consumers unable to correctly judge the authenticity and cost performance of goods, reduce the user stickiness, gradually reduce the flow of e-commerce, and fall into development difficulties. However, live e-commerce is the main channel to break the bottleneck and seek development, which can improve the user experience and tolerance, and increase the flow of e-commerce (Zheng et al., 2017).

\section{Form of Live E-Commerce}

2019 is the first year for the development of live e-commerce. Taobao, Jingdong shopping mall and Tiktok are launching live broadcasting business. The seller or model anchor of the electricity supplier store can broadcast mobile phone products and share trial experience for consumers through live phone and live broadcast software, providing consumers with answers and doubts, providing real and objective real-time services, increasing consumer interaction, and stimulating consumers' desire to buy.

Live e-commerce consists of live platform, anchor, MCN company, brand, supply chain and consumers. The live broadcasting platform is the organizer and rule maker, which formulates live broadcasting rules and traffic distribution. The anchor and the MCN company are content producers, which determine the efficiency and quality of the live broadcast process (Jia and Zhang, 2020). With the development of live broadcast ecommerce, brand providers and supply chain promoters continue to increase their support. Consumers are the target of live e-commerce. All links work closely to jointly promote the continuous expansion of live ecommerce scale and bring more intuitive and vivid shopping experience to consumers. With high conversion rate and good marketing effect, live e-commerce has gradually become a new growth power of e-commerce economy (Jiang, 2020).

\section{The Positive Impact of Live E-Commerce}

Live broadcast e-commerce is a new e-commerce marketing mode. Based on e-commerce, live broadcast is a marketing communication tool, and live broadcast software is used to bring consumer flow to e-commerce and achieve the purpose of e-commerce sales service. At present, live e-commerce has become the mainstream profit channel of e-commerce development, and has entered the dividend stage of economic development of live e-commerce. The positive impact on e-commerce is shown in the following aspects.

\subsection{Consumer Perspective}

Firstly, the audio-visual live e-commerce realizes the personalized promotion of commodity information, enhances the interaction between e-commerce anchor and consumers, and meets the social needs of consumers. Secondly, live e-commerce can watch the introduction and trial video of the use experience of the anchor products to realize consumers' analogical shopping, ensure that their consumption judgment decisions are more real and effective, and improve the user experience.

\subsection{Marketing Perspective}

Compared with the traditional e-commerce marketing, live e-commerce itself is the best advertising which can quickly drive the sales of goods, and make the sales increase intuitively (Xie, 2020). At the same time, live broadcast e-commerce will give benefits back to consumers. They often clear up inventory in the mode of small profit but quick turnover to solve the problem of overcapacity and unbalanced supply and demand. The huge consumer flow and high sales conversion rate of live broadcast e-commerce far exceed that of traditional ecommerce. 


\subsection{Platform Perspective}

Live e-commerce can instantly attract many consumers' attention. By improving the product sales efficiency of platform cooperation and optimizing the service concept of e-commerce platform, the authenticity and user experience of e-commerce products are greatly improved. In addition, the competition of multi live ecommerce platform promotes e-commerce and live broadcasting platform to pay attention to product quality and supply chain protection, improves the core competitiveness of enterprises, and realizes the advantages and innovation of live broadcasting e-commerce in competition.

\section{The Positive Impact of Live E-Commerce}

In 2020, live e-commerce will enter the heyday of national live broadcasting and all-things live broadcasting, but there are also many constraints. First, at this stage, the focus of live e-commerce is on the live anchor and fan flow. All the well-known e-commerce anchor's recommendations place orders, and irrational shopping accounts for a large proportion. Second, live e-commerce anchors are often Internet celebrities, movie stars, government officials, TV hosts, etc. They are often not familiar with the quality, manufacturing technology, and precautions of e-commerce products (Gao, 2020). They only rely on their own attractiveness and brief introduction of products to carry out live delivery. Difference in the live professional abilities will affect the sales volume of e-commerce. Third, the content of live e-commerce is seriously homogenized. On the live ecommerce scene, the anchor usually uses singing, storytelling or dancing to attract consumers (Zheng et al., 2017). The content of live e-commerce is lipstick, cosmetics, etc. The content and form of live broadcasting ecommerce tend to be homogenized without innovation. Fourth, under the wave of nationwide live broadcasting, it is difficult to supervise the quality of e-commerce products and the health of live broadcasting content. Consumers' rights and interests will be infringed if the platform supervision is not in place and the relevant laws and regulations are not formulated and implemented in time, which is not conducive to the development of live broadcasting e-commerce.

\section{Development Strategy of Live E-Commerce}

\subsection{Creating High Quality Live Content and Product Quality}

The core competitiveness of live e-commerce is live content and product quality. The quality of ecommerce products is the guarantee, and the live content is the premise of marketing. Therefore, e-commerce enterprises should pay attention to creating high-quality live content, make e-commerce products intuitive exhibition out of front of consumers, open the market with live content, and finally win the market with quality. This is the root of the sustainable development of e-commerce enterprises and live broadcasting platforms. It needs the live broadcasting platform to cultivate deeply, enrich the live broadcasting content and innovate the live broadcasting form. At the same time, it also needs the e-commerce enterprises to strictly control the product quality.

\subsection{Pay Attention to the Professional Ability of Anchor and Innovate the Form of Live Broadcast}

Live platform should pay more attention to live content and live form to win the public's attention, increase rate of flow and improve product conversion rate. At the same time, we should strengthen the live broadcast publicity and marketing, strictly screen the anchor candidates, cultivate the professional ability of the anchor, or create a live broadcast e-commerce network celebrity in a certain product field to form a unique live broadcast e-commerce style. Combine the professional ability of live e-commerce anchor with innovative live broadcasting form to achieve the live broadcasting effect of " $1+1>2$ ".

\subsection{Focus on Consumer Shopping Experience and Increase User Stickiness}

The audience of live e-commerce is consumers. Consumers' good shopping experience will improve their love for products, and they are willing to be "marketers" of products and recommend them to their relatives and friends, which will imperceptibly enhance the advertising effect of products. Therefore, e-commerce enterprises can introduce VR technology and 3D naked eye technology into live e-commerce so that consumers can have zero distance contact with e-commerce products online and have a deep understanding of e-commerce products. The consumers can therefore enjoy high-quality shopping experience at home and increase user stickiness. 


\subsection{Strengthen Market Supervision to Ensure the Legitimate Rights and Interests of Live Broadcast E-commerce Parties}

Live broadcasting e-commerce covers consumers, live broadcasting platforms, e-commerce platforms, suppliers, anchor brokers and other main organizations. It is necessary for the government to formulate laws and regulations on live broadcasting e-commerce, regulate multiple behaviors, and ensure the legality and compliance of live broadcasting e-commerce. Especially in terms of product quality and consumers' rights and interests, the illegal behaviors of fake and shoddy e-commerce products, live broadcast platform with false propaganda or individual anchor seriously infringe on the legitimate rights and interests of consumers, which requires the government to strengthen market supervision and establish platform supervision and punishment mechanism. We should strengthen the brand cooperation among the live broadcast platform, e-commerce platform and suppliers, and work together to formulate standardized live broadcast e-commerce order and standards to ensure the legitimate rights and interests of the live broadcast e-commerce parties.

\section{Conclusion}

In recent years, live e-commerce has risen and developed to the blowout period. Live e-commerce has made great contributions to improve the product sales performance of e-commerce enterprises and promote the economic development. However, there are many constraints in the development process of live e-commerce. It needs to be solved by live platform, e-commerce platform and brand operators to improve the quality and effect of e-commerce product publicity, and to promote the sustainable development of live new economy and the transformation and upgrading of e-commerce.

\section{References}

1. Gao, H. (2020). Problems and Solutions in E-commerce Live Broadcasting Industry. Nong Jia Can Mou, 19: 183-183.

2. Jia, W. Y., \& Zhang, J. H. (2020). Research on the Development Status and Countermeasures of E-commerce Live Broadcasting. Enterprise Technology and Development, 10: 146-148.

3. Jiang, H. F. (2020). Analysis of the Current Development of Live E-commerce. China Circulation Economy, 22: 7-9.

4. Xie, H. M. (2020). Analysis on Development Status and Optimization Countermeasures of Live Broadcast E-commerce Industry. Marketing Circles (Theory and Practice), 2: 7-7.

5. Zheng, W. S., Wu, J., \& Xie, H. M. (2017). An Analysis of Current Development of E-commerce Live Broadcast and Relevant Strategies. Journal of Jilin Teachers Institute of Engineering and Technology, 33(8): 72-74.

6. Zhong, T. (2020). Analysis on Development Factors, Driving Force and Growth Sustainability of Live Broadcast ECommerce. Commercial Economy Research, 10(18): 85-88.

(Editors: Shulin Liu \& Loly Yan) 